\title{
Fenomena Rendahnya Kinerja Karyawan Bagian Produksi Laksana Home Metal Industri Bandung
}

\author{
I.N. Sundawa ${ }^{1}$, Sumiyati \& R.Purnama \\ Universitas Pendidikan Indonesia \\ Irfan.noor@student.upi.edu
}

\begin{abstract}
The purpose of this study is how much influence the reward system for performance, work discipline on performance and reward systems and work discipline on employee performance. The type of research used is descriptive and verification. The method used in this research is explanatory survey with saturated sample technique and the number of respondents is 71 people. The data analysis technique used in this study is path analysis. The findings of the study on testing the hypothesis are known that reward systems and work discipline affect employee performance simultaneously. Differences found in the object of research, research period, measuring instruments and research results. The author also adds theories from foreign journals and foreign books
\end{abstract}

\footnotetext{
ABSTRAK

Tujuan penelitian ini adalah seberapa besar pengaruh sistem penghargaan terhadap kinerja, disiplin kerja terhadap kinerja serta sistem penghargaan dan disiplin kerja terhadap kinerja karyawan. Jenis penlitian yang digunakan ialah deskriptif dan verifikatif. Metode yang digunakan dalam penelitian ini adalah explanatory survey dengan teknik sample jenuh dan jumlah responden sebanyak 71 orang. Teknik analisis data yang digunakan dalam penelitian ini adalah path analysis. Temuan dari penelitian terhadap pengujian hipotesis diketahui bahwa sistem penghargaan dan disiplin kerja mempengaruhi kinerja karyawan secara simultan. Perbedaan ditemukan dalam objek penelitian, periode penelitian, alat ukur dan hasil penelitian. Penulis juga menambahkan teori dari jurnal asing dan buku asing.
}

\author{
ARTICLE INFO: \\ Article history: \\ Received 20 June 2018 \\ Revised 21 June 2018 \\ Accepted 25 June April 2018 \\ Available online 5 September \\ 2018
}

Keywords:

Employee Performance,

Reward System,

Work Discipline.

\section{Kata kunci:}

Disiplin Kerja,

Kinerja Karyawan,

Sistem Penghargaan.

\section{PENDAHULUAN}

Demi tercapainya tujuan perusahaan, maka diperlukan SDM yang memiliki kinerja yang tinggi. Semakin tinggi kinerja yang karyawan miliki, maka produktivitas perusahaan secara keseluruhan akan meningkat. Dalam suatu perusahaan manajemen sumber daya manusia memiliki peranan yang sangat penting karena tanpa adanya sumber daya manusia yang handal aktivitas produksi bias terhambat dan tujuan perusahaan bisa tercapai. (Purnama, 2008)
Karena, tingginya kinerja yang dihasilkan karyawan menunjukan tugas dan tanggung jawab karyawan mampu di selesaikan secara efektif dan efisien.

Efektivitas dan efisiensi tidak akan berarti bagi pencapaian tujuan perusahaan tanpa didukung oleh sumber daya manusia yang berkualitas. Mintorogo mengemukakan bahwa "sumber daya manusia memegang peranan utama dalam proses peningkatan produktivitas karena alat produksi dan 
teknologi pada hakekatnya merupakan karya manusia.(Samsyul Hadi Senen, 2008)

Laksana Home Metal Industri merupakan salah satu perusahaan milik perorangan yang ikut bersaing dalam industri non migas. Laksana Home Industri merupakan salah satu perusahaan terdepan dan memiliki omzet atau keuntungan yang besar dalam bidang produksi logam dan plastic

Setiap perusahaan akan selalu berupaya agar para tenaga kerja yang terlibat dalam kegiatan perusahaan dapat memberikan kinerja setinggi mungkin untuk mewujudkan tujuan yang telah ditetapkan. Untuk mencapai kinerja maksimum, perusahaan harus menjamin dipilihnya orang yang tepat, dengan pekerjaan yang tepat disertai kondisi yang memungkinkan mereka bekerja optimal.(Mulyadi, Hari dan Marliana, 2010)

Menurut Anwar Prabu (2006:9), Kinerja karyawan adalah prestasi kerja atau hasil kerja (output) baik kualitas maupun kuantitas yang dicapai SDM persatuan periode waktu dalam melaksanakan tugas kerjanya sesuai dengan tanggung jawab yang diberikan kepadanya.(Mulyadi, Hari dan Marliana, 2010). Kinerja pegawai yang baik didukung dengan memiliki kemampuan dan pengetahuan tentang karakteristik pekerjaannya sehingga akan membantu karaywan di dalam menyelesaikan pekerjaannya. (Syamsul Hadi Senen \& Masharyono, n.d.)

Berdasarkan hasil wawancara dengan HRD Laksana Home Metal Industri Bandung, berbagai cara akan di lakukan untuk meningkatkan kinerja karyawan, misalnya dengan pemberian sistem penghargaan, pendidikan dan pelatihan, disiplin kerja, pemberian motivasi dan promosi jabatan karena akan mempengaruhi kinerja karyawan. Salah satu solusi yang tepat untuk meningkatkan kinerja karyawan Laksana Home Metal Industri adalah salah satunya dengan adanya sistem penghargaan. Carraher et al (2006) yang dikutip oleh Hafiza N. S.,
Shah S. S., Jamsheed H., dan Zaman K (2011:328) dalam jurnal Relationship Between Rewards And Employee's Motivation In The Non-Profit Organizations of Pakistan mengatakan bahwa "....that there should be an effective reward system to retain the high performers in the organization and reward should be related to their productivity"'(Shah S. S. Hafiza N. S., \& Zaman, n.d.)

Selain adanya sistem penghargaan, disiplin kerja juga menjadi pemicu rendahnya kinerja karyawan bagian produksi Laksana Home Metal Industri. Dimensi lain yang harus diperhatikan dalam meningkatkan kinerja karyawan yaitu melalui pembinaan dan penegakaan disiplin kepada setiap karyawan, karena disiplin merupakan salah satu faktor yang menentukan keberhasilan suatu kegiatan, disamping kesungguhan dan keahlian. (Moenir,1995:185). (Mulyadi, Hari dan Marliana, 2010)

Disiplin merupakan unsur yang sangat penting dalam meningkatkan kinerja karyawan dalam pencapaian tujuan perusahaan.(Mulyadi, Hari dan Marliana, 2010).

Disiplin kerja yang baik mencerminkan besarnya rasa tanggung jawab. Edi Sutrisno (2011:96) menyatakan bahwa keterkaitan antara Disiplin kerja terhadap kinerja pegawai yaitu Semakin baik disiplin kerja seorang pegawai atau karyawan, maka semakin tinggi hasil kerja (kinerja) yang akan dicapai.(Sutrisno, 2011)

Berdasarkan dari uraian permasalahan yang telah dikemukakan, maka perlu dilakukan penelitian mengenai "Pengaruh Sistem Penghargaan dan Disiplin Kerja Terhadap Kinerja Karyawan Bagian Produksi Laksana Home Metal Industri Bandung".

Adapun tujuan penelitian ini adalah untuk memperoleh hasil temuan mengenai sistem penghargaan dan Disiplin Kerja Terhadap Kinerja Karyawan Bagian Produksi Laksana Home Metal Industri Bandung. 


\section{KAJIAN PUSTAKA}

Definisi dari sistem penghargaan ialah Penghargaan pengakuan atas suatu prestasi yang telah dicapai oleh seseorang akan merupakan motivator yang kuat. Pengakuan atas suatu prestasi, akan memberikan kepuasan yang lebih tinggi daripada penghargaan dalam bentuk materi atau hadiah (Bedjo, 2005). Raymond (2001:11) menyebutkan bahwa "Sistem merupakan sekelompok elemen yang terintegrasi dengan maksud yang sama untuk mencapai tujuan tertentu. Menurut definisi para ahli yang telah dijelaskan sebelumnya, maka dapat didefinisikan bahwa sistem penghargaan kepada karyawan ialah bentuk balas jasa baik finansial maupun non finansial dari perusahaan terhadap karyawan atas kinerja dan prestasi yang dilakukan dalam proses pencapaian tujuan perusahaan.(Raymond Micloed, 2001).

Keith Davis (2005:366) mengemukakan bahwa "Discipline is management action to enforce organization standards". Berdasarkan pendapat Keith Davis tersebut bahwa disiplin kerja dapat diartikan sebagai pelaksanaan manajemen untuk memperteguh pedomanpendoman organisasi (Werther, William B, 2005).

Disiplin kerja adalah Suatu alat yang digunakan para manajer untuk berkomunikasi dengan karyawan agar mereka bersedia untuk mengubah suatu perilaku serta sebagai suatu upaya untuk meningkatkan kesadaran dan kesediaan seseorang mentaati semua peraturan perusahaan dan norma-norma sosial yang berlaku. Berdasarkan pengertian yang telah dijelaskan sebelumnya, maka dapat dikatakan bahwa yang dimaksud dengan disiplin kerja adalah sikap mental yang tercermin dalam perbuatan perorangan maupun kelompok berupa kepatuhan atau ketaatan terhadap peraturan-peraturan yang ditetapkan untuk memperteguh pedomanpedoman organisasi guna untuk mencapai tujuan perusahan dan apabila aturan tersebut dilanggar maka akan mendapatkan sanksi yang telah ditetapkan dan diharapkan dapat mengurangi kinerja yang buruk dari bagian dalam sebuah unit di dalam perusahaan.(Veithzal, 2011)

August W. Smith dalam Sedarmayanti menyebutkan bahwa Kinerja adalah "Hasil atau ukuran dari suatu proses atau pencapaian atau prestasi seseorang berkenaan dengan tugas-tugas yang dibebankan kepadanya" (Sedarmayanti, 2009). Edi Sutrisno pun mengungkapkan "Kinerja (prestasi kerja) karyawan adalah prestasi aktual karyawan dibandingkan dengan prestasi yang diharapkan dari karyawan".(Sutrisno, 2011), Sedangkan menurut Mathis dan Jackson menyatakan bahwa: "Kinerja pada dasarnya apa yang dilakukan atau tidak dilakukan karyawan dan mengemukakan faktor-faktor yang mempengaruhi kinerja karyawan atau pegawai, yaitu : kuantitas input, kualitas output, jangka waktu output, kehadiran tempat kerja, dan sikap kooperatif'(Mathis \& $\mathrm{H}$, 2006).

A.A. Mangkunegara mengungkapkan bahwa: "Kinerja adalah hasil kerja secara kualitas dan kuantitas yang dicapai oleh seorang pegawai dalam melaksanakan tugasnya sesuai dengan tanggung jawab yang diberikan kepadanya".(Mangkunegara, 2009) Menurut Sedarmayanti (2009:174) bahwa "Kinerja merupakan memenuhi atau menjalankan kewajiban suatu nazar, hasil para pekerja, proses organisasi, terbukti secara konkrit, menyempurnakan tanggung jawab, dapat diukur, dapat dibandingkan dengan standar yang sudah ditentukan"(Sedarmayanti, 2009).

Berdasarkan beberapa pengertian diatas, dapat dikatakan bahwa kinerja adalah hasil kerja yang dihasilkan oleh kemampuan dari individu atau kelompok yang dilakukan berdasarkan kecakapan, pengalaman, kesungguhan dan waktu dengan maksimal. 


\section{METODE PENELITIAN}

Objek dalam penelitian ini adalah karyawan bagian produksi Laksana Home Metal Industri Bandung. Variabel bebas dalam penelitian ini adalah sistem penghargaan dan disiplin kerja sedagkan variabel tidak bebas dalam penelitian ini adalah kinerja karyawan. Jenis penlitian yang digunakan ialah deskriptif dan verifikatif. Metode yang digunakan dalam penelitian ini adalah explanatory survey dengan teknik sample jenuh dan jumlah responden sebanyak 71 orang. Teknik analisis data yang digunakan dalam penelitian ini adalah path analysis. Teknik pengumpulan data yang digunakan adalah studi kepustakaan, observasi, wawancara, kuesioner. Sedangkan teknik analisis data yang dilakukan adalah analisis deskriptif dan verifikatif.

\section{HASIL DAN PEMBAHASAN}

Hasil penelitian mengenai sistem penghargaan dan disiplin kerja terhadap kinerja karyawan bagian produksi di Laksana Home Metal Industri Bandung menghasilkan gambaran sebagai berikut:

Dari ketujuh dimensi sistem penghargaan, dimensi kesempatan untuk memenuhi kebutuhan diri sendiri memperoleh total nilai tertinggi yaitu sebesar 3137 (72,7\%). Hal tersebut mengindikasikan bahwa dimensi kesempatan untuk memenuhi kebutuhan diri sendiri telah memberikan kontribusi yang cukup tinggi bagi karyawan dalam mendapatkan sistem penghargaan. Sedangkan untuk dimensi yang memiliki total nilai terendah dalam sistem penghargaan ialah dimensi status dengan skor 350 (70,4\%).

Dari empat dimensi pada variabel disiplin kerja, nilai atau jumlah skor terendah pada variabel disiplin kerja terdapat pada dimensi taat terhadap aturan perilaku dalam jam kerja dengan perolehan skor 1148 (76,9\%) sedangkan dimensi taat terhadap peraturan lainnya di perusahaan memiliki nilai atau jumlah skor tertinggi sebesar $412(82,8 \%)$ artinya dimensi taat terhadap peraturan lainnya di perusahaan berkontribusi cukup tinggi terhadap pencapaian disiplin kerja seorang karyawan.

Dari lima dimensi pada variabel kinerja, nilai atau jumlah skor terendah pada variabel kinerja terdapat pada dimensi Quality of work (kualitas Pekerjaan) dengan perolehan skor $1234(82,7 \%)$ sedangkan dimensi capability (kemampuan) memiliki nilai atau jumlah skor tertinggi sebesar $1491(84,7 \%)$ artinya dimensi capability (kemampuan) berkontribusi cukup tinggi terhadap pencapaian kinerja seorang karyawan.

Hipotesis yang diuji dalam penelitian ini adalah Sistem Penghargaan $\left(\mathrm{X}_{1}\right)$ dan Disiplin kerja $\left(\mathrm{X}_{2}\right)$. Pengujian parsial dapat dilakukan setelah dipastikan adanya pengaruh yang signifikan antara sistem pengahrgaan dan disiplin kerja terhadap kinerja karyawan pada uji simultan.

Pengujian untuk uji F yang diambil dari tabel Anova dengan tingkat probabilitas $(\mathrm{Sig})=$ 0,000 , karena nilai Sig $\leq 0,05$, menunjukan bahwa F hitung $>\mathrm{F}$ tabel $(84,706>3,13)$ maka keputusannya adalah $\mathrm{H}_{0}$ ditolak. Artinya secara simultan (keseluruhan) terdapat pengaruh yang positif antara sistem penghargaan dan disiplin kerja terhadap kinerja karyawan Laksana Home Metal Industri Bagian Produksi Bandung. Hasil pengujian hipotesis secara keseluruhan (simultan) dilakukan secara ulang karena pada variabel Disiplin kerja $\left(\mathrm{X}_{2}\right)$ tidak terjadi pengaruh yang signifikan terhadap variabel $\mathrm{Y}$ dimana $t$ Hitung $\left(\mathrm{X}_{2}=-0,71\right)<$ dari $\mathrm{t}$ Tabel $(1,993)$ dengan tingkat signifikan $>0,05$, maka dilakukan pengujian ulang kembali terhadap Sistem Penghargaan $\left(\mathrm{X}_{1}\right)$

Tabel di atas menunjukan hubungan setiap variabel antara $X_{1}$ dan $X_{2}$. Berdasarkan hasil matriks korelasi antara Sistem Penghargaan, Disiplin Kerja dan Kinerja karyawan Laksana Home Metal Industri Bagian Produksi, diperoleh hasil secara berurutan yaitu Sistem Penghargaan $(0,845)$ dan Disiplin Kerja (0,319). Variabel Sistem Penghargaan memiliki korelasi terbesar yaitu 
sebesar 0,845 dan jika dihubungkan dengan Tabel 3.7 maka tingkat hubungannya sangat kuat $(0,80-1,000)$, hal ini dapat dikatakan bahwa sistem penghargaan merupakan faktor yang semua indikatornya secara lansung berkaitan dengan Kinerja Karyawan. Sedangkan untuk variabel yang memiliki nilai korelasi terendah adalah disiplin kerja sebesar 0,319 dengan tingkat hubungan rendah $(0,20$ 0,399). Hal ini dikarenakan disiplin kerja yang diterapkan di Laksana Home Metal Industri terhadap karyawan nya kurang tepat dan sesuai.

Pengaruh lansung maupun tidak lansung antara Sistem Penghargaan dan disiplin kerja terhadap kinerja yang paling besar pengaruh parsial yaitu pengaruh antara sistem penghargaan terhadap kinerja karyawan sebesar 99,18\% (0,7124:0,710825 x 100\%) dan disiplin kerja memberikan pengaruh sebesar $-0,22 \%(-0,001575: 0,710825 \times 100 \%)$.

Dapat diketahui bahwa koefisien determinasi sebesar 0,714 dan total koefisien jalur dari sistem penghargaan dan disiplin kerja terhadap kinerja karyawan Laksana Home Metal Industri Bagian Produksi Bandung yaitu sebesar 0,710, maka dapat diketahui nilai dari koefisien residu melalui rumus:

$P_{y \varepsilon}=\sqrt{1-R^{2_{Y}(X 1 X 2)}}$

$P_{y \varepsilon}=\sqrt{1-0,710}$

$P_{y \varepsilon}=0,538$

Hasil tersebut menunjukan bahwa sistem penghargaan $\left(\mathrm{X}_{1}\right)$ dan disiplin kerja $\left(\mathrm{X}_{2}\right)$ secara simultan mempengaruhi kinerja (Y) yaitu sebesar $71,1 \%(0,710825 \times 100 \%)$. Sedangkan pengaruh dari luar yang tidak diteliti $(0,538)^{2}=0,289 \times 100 \%=28,9 \%$, dipengaruhi variabel lain yang tidak termasuk ke dalam penelitian ini seperti motivasi, gaya kepemimpinan dan lingkungan kerja.

\section{KESIMPULAN}

Berdasarkan hasil penelitian menyatakan bahwa terdapat pengaruh sistem penghargaan terhadap kinerja karyawan pada Laksana Home metal Industri Bandung dengan thitung sebesar 12,049 secara signifikan sehingga $\mathrm{H}_{0}$ ditolak dan $\mathrm{H}_{\mathrm{a}}$ diterima dengan pengaruh secara lansung sebesar 99,8\%.

Berdasarkan hasil penelitian menyatakan bahwa terdapat pengaruh yang tidak signifikan antara disiplin kerja terhadap kinerja karyawan pada Laksana Home metal Industri Bandung dengan total thitung sebesar -0,71 sehingga $\mathrm{H}_{0}$ diterima dan $\mathrm{H}_{\mathrm{a}}$ ditolak dengan pengaruh sebesar $-0,22 \%$.

Berdasarkan hasil penelitian menyatakan bahwa terdapat pengaruh sistem penghargaan dan disiplin kerja terhadap kinerja karyawan pada Laksana Home metal Industri Bandung dengan $\mathrm{F}$ hitung 84,706 > F Tabel sebesar 3,13 maka dapat dinyatakan secara simultan terdapat pengaruh antara sistem penghargaan dan disiplin kerja terhadap kinerja karyawan Laksana Home Metal Industri Bagian Produksi Bandung dengan pengaruh sebesar $71,1 \%$ dan sisanya sebesar $28,9 \%$ dipengaruhi oleh faktor lain yang tidak termasuk ke dalam penelitian ini seperti, gaya kepemimpinan, motivasi dan lingkungan kerja

Dilihat dari hasil penelitian, menunjukan bahwa disiplin kerja di Laksana Home Metal Industri tidak berpengaruh secara signifikan terhadap Kinerja karyawan. Sehingga disarankan untuk ke depannya penerapan disiplin kerja diperhatikan kembali agar tercapai nya tujuan perusahaan.

\section{DAFTAR PUSTAKA}

Bedjo, S. (2005). Manajemen Tenaga Kerja Edisi Kedua. Jakarta: Erlangga.

Mangkunegara, A. . A. P. (2009). Manajemen Sumber Daya Manusia Perusahaan. Bandung: Remaja Rosda Karya.

Mathis, R. L., \& H, jackson J. (2006). Human Resources Management. Jakarta: Alih bahasa. Salemba Empat.

Mulyadi, Hari dan Marliana, N. (2010). Kinerja Karyawan Pada Departemen Weaving, Volume 9, .

Purnama, R. (2008). Pengaruh Motivasi Kerja 
Terhadap Produktivitas Kerja Karyawan Pada Bagian Produksi Cv . Epsilon Bandung, Volume 7, , 58-72.

Raymond Micloed, J. (2001). Sistem Informasi Edisi 7 Jilid 2. Jakarta: Prenhallindo.

Sedarmayanti. (2009). Manajemen Sumber Daya Manusia dan Produktivitas Kerja. Bandung: Refika Aditama.

Senen, S. H. (2008). Terhadap Produktivitas Kerja Karyawan, 7(September), 1-15.

Senen, S. H., \& Masharyono. (n.d.). Characteristics Dalam Mendukung Universitas Pendidikan Indonesia Mencapai Leading And Outstanding ( Job Performance Analysis Temporary Employee Administrative with Competence and Job Characteristics in Supporting Universitas Pendidikan Indonesia Leading a, 120-137.

Shah S. S. Hafiza N. S., J. H., \& Zaman, K. (n.d.). Carraher et al.

Sutrisno, E. (2011). Manajemen Sumber daya Manusia. Jakarta: Kencana.

Veithzal, R. (2011). Manajemen Sumber Daya Manusia Untuk Perusahaan dari teori ke praktek. Jakarta: Raja Grafindo Persada.

Werther, William B, D. K. (2005). Human Resources and Personnel Management.Fifth Edition. Hill: McGraw. 